\title{
An Examination to Measure the Work Life Balance among Female Faculty Working In Private and Public Universities of Delhi/NCR Region
}

\author{
Pooja Choudhary, Preeti Yadav
}

\begin{abstract}
The study aims to find out the differences in work life balance among Female Faculty working in public and private universities of Delhi/NCR. Researcher has framed an instrument to measure the work life balance among female faculty based on review of literature that was used to collect primary data. Method of data collection was personal and face to face interaction with faculty members. Total sample size of the study was 602 female faculty members. It was found from the study that that the female faculties working in the public universities are more balanced in their work and personal life while, the female faculties working in private universities were found to be less balanced towards their work and life.
\end{abstract}

Keywords: Public universities, Private Universities, Work life balance, Female faculty, Working environment, Occupational stress and India.

\section{INTRODUCTION}

The advancements in the technologies and transforming work patterns demand the more engagement of employees in the work almost making it a $24 * 7$ work environment where the employees have to face numerous challenges, which create more vigilant and industrious sphere. The employees irrespective of their gender have to render their services with complete dedication towards their jobs with the inception of Liberalization, Globalization and Extending Corporate culture over the globe (Mari and Mohideen, 2015). The participation of women in the work culture has been mushrooming with the intervention of several changes taking place in the dynamic environment in terms of changing social perspectives, raising zeal to attain higher standard of living, urbanized system of living, inflation, raising educational levels and growing awareness among the women to make their own place in the society (Pocock et al., 2013; Maiya and Bagali, 2014). They are stepping ahead in multiple fields rendering services to the society as a visible part of the work force. Professional women either married or single have to perform the multiple roles in balancing their personal life as well as professional life. Each role has its fair set of demands from them, there is possibility of overlapping

Revised Manuscript Received on November 11, 2019.

* Correspondence Author

Pooja Choudhary, Research Scholar, Amity Business School, Amity University Rajasthan, Jaipur

Dr. Preeti Yadav, Associate Professor, Amity Business School, Amity University Rajasthan, Jaipur of the demands from distinctive roles, which create many problems for them in their lives and has many ill effects on their physical, psychological, financial and family spheres. Due to their spirit of dedication, they are at time incapable to do justice with all the roles as while performing one role completely, they have to neglect the other. They are found more innovative, work conscious and job committed Women employees face multiple gauntlets in terms of clashes, long span of work, rigid work practices, lack of supportive family, responsibilities of descendants, rising targets, disorganization, long travelling hours, imperfect work schedule and health nuisances etc. (Kumar, 2017; Madpeli, 2013). Work life fit or balance is regarded as a significant measure to enable the women employees to cope with the diversified situations and attain their best. Santhana depicted the significant contribution of the various demographic variables like gender, age, ethnicity, socioeconomic measures, group involvement and cultural practices as the major contributors for creating work life balance among the women employees (Santhana, 2013). The retention and stability of the employees with the increased echelon of the productivity and efficiency act as the main foundation of almost all the institutions and organizational set ups in the contemporary epoch (McDonald et al, 2009). It is generally noticed that the aspect related to work life balance is found closed associated with the work engagement, scale of provisions and strategies framed by the institutions (Purohit, 2013). Employees are given precise opportunities at adequate intervals of time to enable them strike a proper balance in the field of family and work (McDonald et al., 2009). A balance in the work is necessary for long term benefits of the institutions, family, employees as well as society as a whole (Mukhtar, 2012).

\section{REVIEW OF LITERATURE}

Senthil Kumar (2017) examined the challenges encountered by employees for ensuring work life balance. The study was conducted with 60 respondents who were the employees working in telecom companies. The study revealed the challenges faced by employees in terms of imperfect work schedule, long working hours, devotion of time for travelling, irregular meals, rising targets in the institutions, lack of time for the family and spouse.

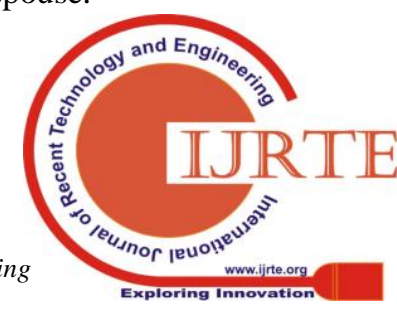




\section{An Examination To Measure The Work Life Balance Among Female Faculty Working In Private And Public Universities Of Delhi/Ncr Region}

The employees working in the private sector had to struggle with more challenges in comparison to the employees working in the public sector. The work life imbalance was found to be a major cause of individual, family, institutional and social disorganization among the employees in the long run. Hence, the study emphasized that companies should provide the employees with economic and non-economic benefits at regular intervals of time to motivate and retain their employees.

Wong et al. (2017) analyzed the association between the workplace factors and work life balance among the employees using some independent variables like co-worker support, flexible work environment and support from supervisor. The sample size of the study was 98 respondents who were the employees in service sector in Kuching, Malaysia. The study highlighted the positive association between the supervisor support, co-worker support and flexible working arrangement. The execution of flexible working environment was found to be highly dependent on the coordination of co-worker and supervisor. The study emphasized that the organizations should formulate and design adequate system to improve the work-life balance. Moreover, management must pay heed to the dynamic needs of the employees and include them in their policies so that they could attain grater work life balance and improve their output and commitment towards the organization.

Naithani (2016) in his study examined the work-life balance in terms of recreation. The study was undertaken with the expatriate academicians who were working in Private higher education institutes in Bahrain, Oman and UAE. The study revealed the magnificent role played by demography in shaping and revitalizing an individual's work-life balance. The study foregrounded and supported the provision of recreation and health dimension on the working of the individuals. The study also highlighted the implementation of all such practices, which aim at fitness of its employees in terms of employee assistance programmes, participation in the campus activities and employee engagement in the decision making process of the institution. There should be suitable mechanisms like promotion of healthy life style among them through promotion of cycling and on-site nutrition counseling to motivate the employees understand their importance.

Leovaridis and Vatamanescu (2015) conducted a comparative analysis of work life balance of high-skilled employees in advertising-marketing, IT\&C, financial-banking, Research and development as well as higher education in Romania using in-depth face-to-face interviews. The study highlighted that the provision of some hours of one's free time for enabling them to finish the tasks was found in IT\&C as well as R\&D sector followed by the banking segment. The teaching department was found entirely engage in preparing lectures, administrative activities and coordinating tasks, which was found to have adverse impact on their family life as well as mental health. Hence, it is stressed that the higher authorities must plan effective ways to enable the employees sparing some time and spend that with their family members. This is an effective measure to boost the morale and productivity of employees. Yadav and Rani (2015) conducted a study to examine the various factors influencing the work life balance among the married women. The study revealed that stress, age, existence of competitors on the work place turf, lack of support from the family members as well as husband, institutional conflicts and the complexity in setting the priorities as the major factors, which affect the psychology and health related aspects of working women in the contemporary era. The study also found the married women incapable of devoting sufficient and qualitative time to their family members. These factors were also observed to have a negative impact on the health and their relationships. Hence, the study emphasized that the organizations should focus on developing suitable strategies like organization of workshops and training programs; implement some significant ways such as employee appreciation, responsibility sharing and involvement of employees in decision making to create a balanced work environment.

Doble and Supriya (2015) examined the perceptions of employees with regard to the work life balance in the service sector. The sample size of the study was 110 female and male employees who were the IT professionals in Pune. The research stated that both the genders experienced the imbalance in their work life at the same scale and made their preferences for part time jobs as well as job from homes. Majority of the employees struggled with the stress due to the non-availability of their childcare facilities. Female employees preferred the pliable jobs, which could enable them look after their family members. Besides this, the flexible working hours enhanced the quality of the employees' life. Therefore, the study stressed on the provision of a congenial and compatible working environment to enable the employees devote their best for the institution and enable them to nurture their family as well. It would also act as an important mechanism to increase the output and productivity of the employees.

Dhas and Karthikeyan (2015) illuminated the major gauntlets as well remedial measures in context to the work life balance in the modern era. In the highly competitive environment, the management prefer to recruit the employees who are quiet sincere with regard to their work engagement, dedication and capable ample to strike a balance in their work as well as family life. The study elucidated age factor, gender of the employees, personal interests as well as work environment as the major constraints, which influence the work life patterns and practices of the employees working across numerous distinctive domains. The researchers stressed on providing a supportive as well as encouraging environment to enable the employees harness their full potentials and lead to optimum level of benefits to the employees and organization as well Management must lay down flexible policies and strategies to enable the employees manage their family and work culture in a better way.

Nahkamaki (2015) ascertained the various factors positively and negatively influencing the work life balance of employees. The highly demanding work environment has been reckoned as the root cause of stress, burn out and poor quality of life. The sample size of the study was 82 operators working in the Finnish game industry.

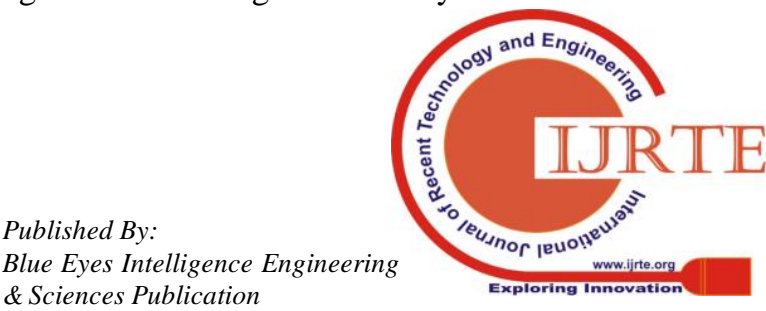


The study observed the good perceived work-life balance among the operators of Finnish game industry. Finland was reported as the nation having highest work-life balance rate. Research highlighted operators' gender and role in the industry acted as the main factors that influenced their work life balance the most. The overall intensity of work, long working hours and continual connectivity to work were the negative factors, which led to work life conflict their lives. Flexible working hours was the most preferred strategy by the operators to enhance their productivity, reduce the stress level among them as well as meet the demands of the dynamic and diversified industry.

Tavassoli and Sune (2015) investigated the outcomes of work life balance as well as mediating role of culture in Iranian employees with reference to humane orientation, gender egalitarian, collectivism and temporal flexibility. The study stated nature of work environment could be an influential factor in balance gain and balance losses in terms of life stability or work-life conflict. Work life balance was found to be positively associated with low level of psychological strain, high level of job and life satisfaction. Psychological distress would increase along with the conflict between the life and work of employees. Work life balance was also supported to have a moderating impact of culture in terms of high humane orientation and other aspects. Therefore, emphasis must be laid down over the strategies for making the people psychologically sound so that the employees could be able to meet their demands of work and non-work roles.

The Council of Economic Advisers (2014) highlighted the factors and challenges that influence the work life balance among the working employees. The rising demands for higher level of productivity, employee commitment, higher level of stable devotion towards the work and $24 * 7$ employee engagement have brought a huge transformation in the perspectives and expectations of the employees. Women employees complain more about the imbalance as compare to their male counterparts. The higher level of stress due to changing work patterns has negative impact on the physical as well as psychological health of the employees in terms of mental ailments, fatigue, and ill health. The individuals have been found making their preferences for the part time jobs to save time and energy for looking after the families. Therefore, it was suggested that management should formulate suitable strategies and plan effective training sessions to motive the employees balancing their spheres and have a peaceful living.

Pringle et al., (2014) documented the experiences and perceptions of women holding positions in senior management in public as well as private sector organizations. Women have entered the turf to earn and nurture their family members. The study revealed the multiplicity of gauntlets, negotiated spaces as well as excitements in the lives of working women. They are exposed to the discourse of exclusion from the senior management roles, which is of central concern. Rather, the study highlighted the acceptance of work-life choices concept at the place of work-life balance. The successful working women have adopted to remain single, postponement of their jobs as well as preferred to be a single parent so that they could be able to establish themselves in the highly complex and male dominated society. The study suggested that the

experiences of the highly successful women must be brought into the notice of the working women so that others could get inspiration and proceed in their lives.

N. \& Uddin et al., (2013) ascertained and highlighted the experiences, challenges and expectations of employees regarding their work life balance. The changing work patterns, raising cost of living standard, increasing awareness among women and concept of nuclear families have acted as push factors for influencing them enter the employment arena; earn living for their families and establish themselves as a successful breadwinners. The sample size of the study was 320 respondents who were the teachers at educational institutions in Bangladesh. The study documented the difficulties faced by working women to cope up with the diverse exigencies of work place and their family members. The respondents were found themselves to be stuck with the all-time commitment work attitude. This aspect was also found as a major cause of their family conflicts and disorganization. The employees should be provided with the flexible working hours, residential and childcare facilities to manage the complexities of life.

Objectives:To find out the differences in work life balance among Female Faculty working in public and private universities of Delhi/NCR.

\section{RESEARCH METHODOLOGY}

In current study researcher has used both the primary and secondary data. Secondary data related to the work life balance studies, higher education system of India, universities and its types, and knowledge about the research methodology, has been used in the study. For secondary data researcher has used books, research reports, research databases, websites, newspapers and government reports. While the major objectives of the study have been achieved using primary data only. Primary data is collected in the form of perception of female faculty members towards the work life balance in public and private universities of Delhi/NCR. 600 questionnaires were distributed to the female faculty of the public universities and 300 questionnaires were distributed to the female faculty of private universities. Out of which only 443 female faculty from public universities, and 159 female faculty from private universities; completely filled up the form, which have been used for final data analysis. The response rate was 73 percent for the public universities and 53 percent for the private universities. Total number of respondents of the study were counted as 602 female faculties. Hence, total sample size will be 602 female faculty members. Researcher has framed an instrument to measure the work life balance among female faculty based on review of literature that was used to collect primary data. Method of data collection was personal and face to face interaction with faculty members. In current study researcher has used random sampling method, as the female faculty from all the 12 universities have been selected randomly from each of the university. Researcher has visited all the departments of the 12 selected universities and approached female faculty to collect the data. 


\section{An Examination To Measure The Work Life Balance Among Female Faculty Working In Private And Public Universities Of Delhi/Ncr Region}

$H_{0}$ : There is no significant difference in the work life balance among Female Faculty of the Public and Private universities of Delhi/NCR.

$H_{1:}$ There is significant difference in the work life balance among Female Faculty of the Public and Private universities of Delhi/NCR.

\section{FINDINGS AND DISCUSSIONS}

Current study aims to measure the work life balance among female faculty working in public and private universities of Delhi/NCR region. A separate section was developed for this purpose in the questionnaire, consisting total 27 statements which can provide the information related to the work life balance among female faculty. These statements have been rated using five point scale and results of the data analysis have been shown using tabulation method.

Researcher has developed the questionnaire to collect the data related to the perception of the female faculty towards the work life balance, hence it is required to measure the reliability of the questionnaire. Results of the reliability has been given in this section.

Table 1: Reliability Results

\begin{tabular}{|l|l|l|l|l|}
\hline $\begin{array}{l}\text { Descrip } \\
\text { tion }\end{array}$ & $\begin{array}{l}\text { Number } \\
\text { of } \\
\text { Statement } \\
\text { s }\end{array}$ & $\begin{array}{l}\text { Number } \\
\text { of } \\
\text { Respondent } \\
\text { s }\end{array}$ & $\begin{array}{l}\text { Cronbach's } \\
\text { Alpha }\end{array}$ & Remarks \\
\hline $\begin{array}{l}\text { Work } \\
\text { life } \\
\text { balance }\end{array}$ & 27 & 602 & .964 & $\begin{array}{l}\text { Vxcellent } \\
\text { Value } \\
\text { (Alpha value } \\
\text { above 0.90 }\end{array}$ \\
\hline
\end{tabular}

Interpretation: Reliability shows the consistency in the responses of the respondents, hence it is important parameter to measure the normality of the data, and the reliability of the results generated based on the data collected using the reliable questionnaire. Here, in current study, researcher has used Cronbach Alpha method to measure the reliability of the data. The value of alpha is found above 0.70 , it is considered as acceptable value, and questionnaire is considered as reliable to be used for the further data analysis. In current study, the reliability of this section was calculated using Cronbach Alpha method that was developed to measure the work life balance among female faculty working in public and private universities of Delhi/NCR region. The total number of statements in this section were 27 and the number of respondents in the study were 602 female faculty. The value of Alpha was found to be 0.964 , which is above 0.90 and near to one, which is considered as excellent value and this section of the questionnaire was found to be reliable. Any results based on the data collected using these statements will give true picture of the construct.

\section{DESCRIPTIVE ANALYSIS}

This section comprises the results of the descriptive analysis done using mean, standard deviation and the skewness for all the 27 statements framed to measure the wok life balance among female faculty working in public and private universities of Delhi/NCR region.

\begin{tabular}{|c|c|c|c|c|c|}
\hline \multicolumn{6}{|c|}{ Table 2: Descriptive Statistics } \\
\hline & $\mathrm{N}$ & Mean & Std. Deviation & Ske & ness \\
\hline & Statistic & Statistic & Statistic & Statistic & Std. Error \\
\hline I feel completely fit and fine in my life. & 602 & 3.2027 & 1.29845 & -.280 & .100 \\
\hline I give proper time for yoga/exercise/routine check-ups. & 602 & 3.3654 & 1.14476 & -.195 & .100 \\
\hline $\begin{array}{l}\text { I get enough time for enhancing my learning, or further } \\
\text { education. }\end{array}$ & 602 & 3.3439 & 1.24517 & -.409 & .100 \\
\hline $\begin{array}{l}\text { I never miss the precious moments of my life (birthdays, } \\
\text { anniversaries, or festivals) due to my job. }\end{array}$ & 602 & 3.3223 & 1.31514 & -.284 & .100 \\
\hline $\begin{array}{l}\text { I never feel bore from my routine life, and can easily } \\
\text { manage time for my hobbies as well. }\end{array}$ & 602 & 3.2857 & 1.30585 & -.333 & .100 \\
\hline I take proper care of my kids. & 602 & 3.2708 & 1.39697 & -.256 & .100 \\
\hline $\begin{array}{l}\text { I spend time with my kids and never ignore kids due to } \\
\text { work overload. }\end{array}$ & 602 & 3.2907 & 1.42484 & -.279 & .100 \\
\hline
\end{tabular}




\begin{tabular}{|c|c|c|c|c|c|}
\hline I never miss parent teachers meet due to my job. & 602 & 3.3571 & 1.25475 & -.282 & .100 \\
\hline $\begin{array}{l}\text { I feel satisfied that I am contributing a lot towards the } \\
\text { growth of my kids along with my job. }\end{array}$ & 602 & 3.5183 & 1.16686 & -.467 & .100 \\
\hline I am enjoying a healthy married life. & 602 & 3.5947 & 1.17028 & -.539 & .100 \\
\hline $\begin{array}{l}\text { My husband never complained to me due to my job or } \\
\text { working hours. }\end{array}$ & 602 & 4.2010 & 1.08743 & -.255 & .100 \\
\hline I take care of my family members at my best. & 602 & 4.1279 & 1.10899 & -.121 & 100 \\
\hline $\begin{array}{l}\text { I never ignore the health or any other needs of aged } \\
\text { family members due to my job. }\end{array}$ & 602 & 4.1545 & 1.07353 & -.145 & .100 \\
\hline I do my job with perfection. & 602 & 3.7076 & 1.40746 & -.847 & .100 \\
\hline $\begin{array}{l}\text { I got adequate reward or recognition for my efforts in } \\
\text { universities. }\end{array}$ & 602 & 3.8040 & 1.27099 & -.853 & .100 \\
\hline $\begin{array}{l}\text { My colleagues and supervisors give respect to me and } \\
\text { make me feel motivated. }\end{array}$ & 602 & 3.9767 & 1.35022 & -.934 & .100 \\
\hline I never feel overburdened or stressed out due to my job. & 602 & 2.7475 & 1.00218 & -.304 & .100 \\
\hline $\begin{array}{l}\text { I gets enough time for lunch, for feeding my kids or } \\
\text { liberty to talk to my family over phone during free } \\
\text { hours. }\end{array}$ & 602 & 3.1894 & 91975 & -.641 & 100 \\
\hline $\begin{array}{l}\text { I can easily cope up with the routine work if I get late for } \\
\text { office sometimes. }\end{array}$ & 602 & 3.2542 & .87116 & -.759 & .100 \\
\hline $\begin{array}{l}\text { I have easily managed with my new born baby or school } \\
\text { going kids and teaching job. }\end{array}$ & 602 & 3.1395 & .77854 & -.439 & .100 \\
\hline $\begin{array}{l}\text { I never feel that I have not enjoyed my motherhood due } \\
\text { to my teaching job. }\end{array}$ & 602 & 3.0233 & .79272 & -.544 & .100 \\
\hline $\begin{array}{l}\text { I never felt that I am not an active member of my family, } \\
\text { or not cooperating due to my job. }\end{array}$ & 602 & 3.1877 & 1.01551 & -.976 & .100 \\
\hline My married life never gets suffered due to my job. & 602 & 3.1993 & .98075 & -.864 & .100 \\
\hline I give full attention to the career of my children. & 602 & 3.5083 & 1.10245 & -.559 & .100 \\
\hline $\begin{array}{l}\text { I have always given time for my personal growth and } \\
\text { advancement along with my job. }\end{array}$ & 602 & 3.5847 & 1.11575 & -.614 & .100 \\
\hline $\begin{array}{l}\text { I never neglected my health or the health of my kids due } \\
\text { to my working life. }\end{array}$ & 602 & 3.5515 & 1.11330 & -.703 & .100 \\
\hline
\end{tabular}




\begin{tabular}{|l|c|c|c|c|c|}
\hline $\begin{array}{l}\text { I can enjoy fully without any tension of work while on } \\
\text { family tour, or holidays, or on festivals. }\end{array}$ & 602 & 3.3588 & 1.35319 & -.603 & .100 \\
\hline Valid N (list wise) & 602 & & & & \\
\hline
\end{tabular}

Interpretation: Data has been collected from 602 female faculties working in twelve public and private universities situated in Delhi/NCR region. The highest mean value was found to be 4.20 , for the statement 'My husband never complained to me due to my job or working hours', followed by the statement 'I never ignore the health or any other needs of aged family members due to my job' and 'I take care of my family members at my best' with mean value of 4.15 and 4.12 respectively. While the lowest mean value was found 2.74 and 3.02 for the statements 'I never feel overburdened or stressed out due to my job' and 'I never feel that I have not enjoyed my motherhood due to my teaching job'. Hence, it can be said that female faculty were found to be highly balanced in their personal and professional life as they give proper time to their husband after working hours, and never ignore their health and take proper care of their health, and their family members. While, the female faculty were found to be unable to balance their personal and professional life as they feel overburdened in their job and never enjoy their motherhood because of their teaching job. Further, the value of standard deviation for all the 27 statements were found to be less than or close to one, which indicates that there is no such variation in the responses of female faculty towards the work life balance among female faculty working in public and private universities of Delhi/NCR. The skewness was measured to check the normality of the data, the value of the skewness lies between -1 to 1 is considered as normal data, while the value lies out of these limits will termed as skewed data. In current study, the value of skewness lies between minus one to one, hence data is termed as normally distributed and results obtained using this data can be generalized on the population. The missing value stats shows that there is no missing value in the data, and data has been screened before doing final analysis. Overall, it can be said that the descriptive analysis conducted on the data showed that there is consistency in the responses of the female faculty, and it's normally distributed. Further, the mean value analysis showed that universities need to work upon the flexible working hours for female faculty, so that they can take care of their husband, and family members, can give time to their kids too. Teaching work load should be as per UGC standard and should not exceed than the limit or capacity of an individual as it may make faculty feel overburdened which causes imbalance in work and personal life. The overall mean values for all the 27 statements were found to be above two which shows that the overall the level of work life balance among female faculty working in private and public universities was average only, neither too high nor too low.

$H_{0}:$ There is no significant difference in the work life balance among Female Faculty of the Public and Private universities of Delhi/NCR.

$H_{1:}$ There is significant difference in the work life balance among Female Faculty of the Public and Private universities of Delhi/NCR.

Researcher has used independent sample t-test to measure the difference in the mean values of the variable 'work life balance' among two groups of female faculty, one who is working in public universities and another group of female faculties working in private universities. Both these groups are independent in nature, and opinions and perception of one group do not get affected by the opinions or perceptions of another group.

\begin{tabular}{|l|l|c|c|c|c|}
\hline \multicolumn{7}{|c|}{ Table 3: Work Life Balance } \\
\hline & $\begin{array}{l}\text { University } \\
\text { Type }\end{array}$ & $\mathrm{N}$ & Mean & $\begin{array}{c}\text { Std. } \\
\text { Deviatio } \\
\mathrm{n}\end{array}$ & $\begin{array}{c}\text { Std. } \\
\text { Error } \\
\text { Mean }\end{array}$ \\
\hline $\begin{array}{l}\text { Work } \\
\begin{array}{l}\text { Life } \\
\text { Balanc } \\
\mathrm{e}\end{array}\end{array}$ & $\begin{array}{l}\text { Public } \\
\text { University }\end{array}$ & \begin{tabular}{c}
44 \\
\cline { 2 - 6 }
\end{tabular} & $\begin{array}{c}3.887 \\
2\end{array}$ & .41261 & $\begin{array}{c}.0196 \\
0\end{array}$ \\
\hline & $\begin{array}{l}\text { Private } \\
\text { University }\end{array}$ & $\begin{array}{c}15 \\
9\end{array}$ & $\begin{array}{c}2.249 \\
1\end{array}$ & .46567 & $\begin{array}{c}.0369 \\
3\end{array}$ \\
\hline
\end{tabular}

Interpretation: The mean value of the variable 'Work life balance' was found to be higher for the public university i.e. 3.88 , while the mean value for the variable 'Work life balance' was found to be lowest for private universities. It shows that the female faculties working in the public universities are more balanced in their work and personal life while, the female faculties working in private universities were found to be less balanced towards their work and life. Further, the work life balance has been measured using five point scale, hence the mean value in case of public universities was found to be above three which shows that the work life balance among female faculties working in private universities was above average, while the work life balance among female faculties working in private universities was found to be average only based on the mean value, which is less than three. Hence, public universities are providing better facilities to its faculties to help them in balancing their personal and professional life. 


\begin{tabular}{|c|c|c|c|c|c|c|c|c|c|c|}
\hline & & & able 4 & Results & f Indepen & dent Sam & le T-Test & & & \\
\hline & & $\begin{array}{r}\text { Levene's } \\
\text { for Equal } \\
\text { Varian }\end{array}$ & $\begin{array}{l}\text { Test } \\
\text { ity of } \\
\text { ces }\end{array}$ & & & t-test & or Equality o & Means & & \\
\hline & & $\mathrm{F}$ & Sig. & $\mathrm{t}$ & df & $\begin{array}{c}\text { Sig. } \\
\text { (2-tailed } \\
\quad)\end{array}$ & $\begin{array}{c}\text { Mean } \\
\text { Difference }\end{array}$ & $\begin{array}{l}\text { Std. Error } \\
\text { Difference }\end{array}$ & $\begin{array}{r}95 \% \text { Co } \\
\text { Interva } \\
\text { Diffe }\end{array}$ & $\begin{array}{l}\text { fidence } \\
\text { of the } \\
\text { ence }\end{array}$ \\
\hline & $\begin{array}{l}\text { Equal } \\
\text { variances } \\
\text { assumed }\end{array}$ & 4.452 & .035 & 41.476 & 600 & .000 & 1.63814 & .03950 & 1.56058 & 1.71571 \\
\hline & $\begin{array}{l}\text { Equal } \\
\text { variances } \\
\text { not } \\
\text { assumed }\end{array}$ & & & 39.180 & 252.423 & .000 & 1.63814 & .04181 & 1.55580 & 1.72049 \\
\hline
\end{tabular}

\section{Interpretation}

The results of levene's test and t-test were used to test the hypothesis in the current study. Levene's test value was found to be 4.452 , at a p-value of 0.035 , which indicates that there is a significant difference in the variance of the two groups of respondents' i.e. female faculties from public and private universities. As the variance for public and private universities for the variable 'Work life balance' was found to be significantly different, hence the value of t-test was taken when the unequal variance was assumed between two groups. The value of t-test corresponding to the unequal variance was found to be 39.180 , at a p-value of 0.000 , which indicates that there is a significant difference in the mean values of the variable 'Work life balance'. Hence, the null hypothesis got rejected and alternate hypothesis got accepted in the study, which states that there is a significant difference in the work life balance among Female Faculty of the Public and Private universities of Delhi/NCR. Overall, it can be said that the private universities are not providing the various facilities to female faculties that can help in balancing the work and professional life. While public universities are better in this area and providing full facilities to help the female faculties in balancing their work and personal life.

\section{CONCLUSION}

Overall, it can be concluded that the mean value of public university was found to be higher than private university for all the statements used to measure the work life balance among female faculties working in public and private universities. This shows that the public universities are focusing higher than private universities for balancing the work and life of their female faculties. There is a difference in the working environment of both the public and private universities, hence there is a huge difference in the work life balance of female faculties of both type of universities. Public universities provide higher facilities to the female faculty, with high level of job security, and comparative good pay scale, which keeps the female faculty more balanced in their work and life.

\section{REFERENCES}

1. Dhas, D. B and Karthikeyan, P. (2015), "Work-Life Balance Challenges and Solutions: Overview", International Journal of Research in Humanities and Social Studies, Vol. 2, Issue 12, December 2015, pp. 10-19.

2. Nahkamaki, Riikki (2015), "Work-Life Balance in the Finnish Game Industry", Bachelor Thesis Submitted at Jamk University of Applied Sciences, 2015, pp. 1-62.

3. Nithanni, Pranav (2016), "Impact of Health and Recreation in Work life Balance: A Case Study of Expatriates", Munich Personal RePE and Archive, 2016, pp. 1-23.

4. Peetz, D. Muurlink, O., Townsend, K, Allan, C and Fox (2011), "Quality and Quantity in Work Home Conflict: The Nature and Direction of Effects of Work an Employees' Personal Relationships and Partners", Australian Bulletin of Labour, Vol., 37, Issue 2, 2011, pp. 138-163.

5. Potgieter, Sonia C. B and A. Barnard (2012), "The Construction of Work-Life Balance: The Experience od Black Employees in A Call-Centre Environment", SA Journal of Industrial Psychology, Vol. 36, Issue 1, pp. 1-8.

6. Pocock, B. Charlesworth S. and Chapman J. (2013), "Work Family and work Life Pressures In Australia: Advancing Gender Equality in 'Good Items'?", International Journal of Sociology and Social Policy, Vol. 33, Issue 9-10, 2013, pp. 594-612.

7. Pringle, J. K., Su Olsson and Robyn Walker (2014), "Work-Life Balance for Senior Women Executives: Issues of Inclusion?",Gender Perspectives and Management, University of Auckland, New Zealand, 2014, pp. 1-16.

8. Purohit, Manisha (2013), "A Comparative Study of Work Life Balance in Various Industrial sectors in Pune Region", International Journal of Marketing, Financial Services and Management Resaerch, Vol. 2, Issue 3, 2013. Pp. 4-16

9. Santhana Lakshmi K, Sujatha Gopinath S. (2013), "Work Life Balanceof Women Employees with Reference to Teaching Faculties, International Monthly Refereed Journal of Research in Management and Technology, Vol. 2, 2013, pp. 25-35. 
An Examination To Measure The Work Life Balance Among Female Faculty Working In Private And Public Universities Of Delhi/Ncr Region

10. Senthilkumar, K. M., R P Ezhilmuthu, Praveen (2012), "Preparation and Characterization of Nabumestome Liposomes", International Journal of Life Sciences Biotechnology and Pharma research, Vol. 1, Issue 1, 2012, pp. 71-82.

11. Sigroha, Anju (2014), "Impact of Work Life Balance on Working Women: A Comparative Analysis", The Business and Management Review, Vol. 5, Number 3, 2014, November 2014, pp. 22-31.

12. Tavassoli, Tara and Albert Sune (2015), "Research Proposal on the Outcomes of Work-Life Balance in Spain and Iran", Working Paper, 2015, pp. 1-10.

13. The Council of Economic Advisers (2014), "Work-Life Balance and the Economics of Workplace Flexibility”, Executive Office of United States, June 2014, pp. 1-35.

14. N. Hoque and Uddin M. S. et al. (2013), "Work Life Balance: A Study on Female Teachers of Private Education Institutions of Bangladesh", European Journal of Business and Management, Vol. 5, Issue 13, 2013, pp. 10-17.

15. Vijayalaxmi, Naveetha (2013), "Work Life Balance of Women Working in Educational Institutions: Problems and Issues", International Journal of Research in Commerce, Economics and Management, Vol. 3, Issue 4, 2013, pp. 73-75

16. Wong, P. W., Bandar, N. F. A and JamayahSaili (2017), "Workplace Factors and Work Life Balance among Employees in Selected Service Sector", International Journal of Business and Society", Vol. 18, Issue S4, 2017, pp. 667-684.

17. Yadav, R. K. and NishantDabhade (2014), "Work life Balance and Job Satisfaction among the Working Women of Banking and Education Sector- A Comparative Study", International Letters of Social and Humanistic Sciences, Vol. 21, 2014, Pp. 181-201.

18. Yadav, Taruna and Rani, Sushma (2015), "Work Life Balance: Challenges and opportunities", International Journal of applied Research, Vol. 1, Issue 11, 2015, pp. 680-684. 